\title{
The Role of Mitochondria in Generating Different Submaximal Strength and Endurance Capabilities in Elderly People
}

Carmeli E*

Department of Physical Therapy, University of Haifa, Israel

*Corresponding author: Carmeli E, Associate Professor, Department of Physical Therapy, University of Haifa, Israel, Tel: 972-4-828-8397; E-mail: ecarmeli@univ.haifa.ac.il

Received date: June 19, 2017; Accepted date: June 22, 2017; Published date: June 26, 2017

Copyright: () 2017 Carmeli E. This is an open-access article distributed under the terms of the Creative Commons Attribution License, which permits unrestricted use, distribution, and reproduction in any medium, provided the original author and source are credited.

\begin{abstract}
This editorial note scrutinizes an important clinical opinion regarding the role of mitochondria in generating differing strength and endurance capabilities in elderly vs. young people. The submaximal effort against resistance, as well as endurance effort differs between young vs. elderly people. This is usually explained by neurophysiological differences, but this editorial note presents a hypothesis regarding the aging mitochondria. Mitochondria in young people obtain all the necessary physical and metabolic properties that are needed and acquired throughout adulthood; yet, mitochondria in elderly people undergo many changes.
\end{abstract}

Keywords: Aging; Exercises; Mitochondria; Muscle; Strength

\section{Introduction}

Young adults' response to resistance and endurance exercise differs from that of elderly people in four aspects. [1] 1) Neurophysiological, based on maximal and submaximal isometric or isotonic voluntary force, motor unit thresholds, force kinetics and endurance. [2] 2) Biochemical, for example, young people have a more glycolytic metabolism and produce higher blood lactate after maximal isometric/ isotonic contraction, and demonstrate slower utilization of muscle glycogen and blood glucose. [3] 3) Biological, in terms of expression and activation of adult stem or satellite cells during normal growth, and 4) Morphological, muscle fiber composition differs between young and elderly people.

This editorial note introduces the theory that aging mitochondria affect the ability to generate submaximal strength and to produce endurance capabilities, and suggests potential explanations.

\section{The Mitochondria}

Mitochondria are the cell's powerhouse, producing energy necessary for basic and advanced myofiber functions, such as contraction, myogenesis, apoptosis and hypertrophic changes. Consequently, mitochondria are responsible for most of the oxygen consumption and most of the adenosine triphosphate (ATP) production within the myofibers.

Two different populations of mitochondria exist in skeletal muscle: A small population (approximately $20 \%$ of total mitochondria) are subsarcolemmal mitochondria, located below the plasma membrane. A larger population $(80 \%$ of mitochondrial) are intermyofibrillar mitochondria, organized between the myofibrils. These two populations have specific biochemical and functional properties. They perform differently during aging and are differentially involved in the process of primary sarcopenia. [4], the subsarcolemmal mitochondria generate higher levels of reactive oxygen species [5]; therefore, peak $\mathrm{VO}_{2}$ differs between young and elderly people. [6], about $2 \%$ to $3 \%$ of the electrons that flow through the electron transport chain of complexes I-IV are not completely reduced to water and form oxygen free radicals like superoxide $\left(\mathrm{O}_{2}^{-}\right)$and hydroxyl radical $\left(\mathrm{OH}^{-}\right)$. In elderly mitochondria, these percentages are higher. [7,8], moreover, mitochondria are considered the most important cellular sources and targets of free radicals [9].

Although mitochondria can be found nestled between muscle myofibrils, they are not "sedentary" organelles, but rather, vibrant ones. In young people, mitochondria are always in transit and regularly undergo fission and fusion. During aging, the fission and fusion cycles of mitochondria are regulated by complex molecular machinery. Evidence [10] demonstrates mitochondrial hyperfusion, which could represent an attempt to cope with increased levels of mtDNA mutations. Instabilities and variability in the fusion and fission of mitochondria may be responsible for the formation of aberrant, i.e. giant or elongated mitochondria in senescence [11], which could lead to increased oxidant production. In young people, mitochondria frequently move toward specific subcellular locations such as the Zbands and are thus, more available for immediate contraction. In addition, in young people mitochondria appear more frequently in type I muscle fibers and are typically located next to the Z-band, whereas in elderly people, the mitochondria appear less frequently in types I and II muscle fibers, and are mostly located peripherally.

The theory that mitochondrial function becomes impaired and often mutates with aging, is well-established. [12], mitochondrial malfunction, as well as decreased mass and number is associated with aging muscle (i.e., primary sarcopenia).

Another possible explanation for the difference in young as compared to elderly people in their ability to produce energy for muscle contraction is a phenomenon known as 'mitochondrial respiratory chain disorder' (MRCD). [13] MRCD is probably one of the most common, yet often under-diagnosed disorders, resulting in nonspecific symptoms of metabolic abnormality.

The process by which an organism adapts to a specific mechanical stress is known as mitochondrial hormesis theory. This theory based on a J-shaped curve representing the concept that very low or very 
high exposure to physical exercises is harmful or useless, while moderate exposure is advantageous or even necessary. The same concept applies to either short or long duration of muscle contraction. The differing behavior and nature of mitochondria in young people as compared to old people might be explained by the mitohormesis/ mitochondrial hormesis phenomenon [14].

In addition, mitochondrial dysfunction may result in changes in the myonuclei and directly diminish ATP, which would negatively impact protein synthesis within myofibers and probably decrease whole-body bioenergetics. [15], there is evidence that mitochondrial turnover is altered during muscle aging [16], and reduced mitochondrial functions (e.g., efficiency and aerobic capacity) are associated with slower gait speed [17].

Young people perform better and are more adaptable to endurance/ aerobic exercises than elderly people are, because their energy expenditure relies more on oxidative and glycolytic metabolism. Moreover, the efficacy of both anaerobic/glycolytic activity and oxidative/aerobic activity is age-dependent. [18], utilizing various energy mechanisms can significantly facilitate muscle metabolic status. However, glycolysis in skeletal muscle in elderly people is much more difficult to achieve than is using oxidative, energetic system muscle. In other words, it is more difficult for elderly people to optimally use the glycolytic metabolism essential to produce submaximal muscle contraction, than it is for them to optimally use the oxidative energy system.

Quantitative genetic epidemiology studies have provided information related to mtDNA and mtRNA and exercise. Exerciseinduced changes demonstrate different gene expression as people grow and age [19].

Other findings demonstrated that satellite cells (i.e. adult stem cells) have an indirect role in the quality of the metabolic and energetic systems. The satellite cells retain certain myogenic gene expression for distinct metabolisms that help illustrate the differences in functional parameters for mitochondrial biology. [20], mitochondrial organization and function are linked to differentiation and/or proliferation of adult stem cells and decline during aging. Mitochondrial activity has a critical role in the differentiation and proliferation of satellite cells; thus, the activation of endogenous adult stem cells is strongly related to mitochondrial motility.

\section{Conclusions}

The effects of malfunction and dysfunction of mitochondria during aging can support the theory that these phenomena could translate into a progressive decrease in muscular performance, influence submaximal muscle contraction and aerobic capabilities, and eventually, lead to the development of primary sarcopenia.

\section{References}

1. Gabel L, Macdonald HM, Nettlefold L, Race D, McKay HA (2016) Reference data for jumping mechanography in Canadian children, adolescents and young adults. J Musculoskelet Neuronal Interact 16: 283-295.

2. Cohen R, Mitchell C, Dotan R, Gabriel D, Klentrou P, et al. (2010) Do neuromuscular adaptations occur in endurance-trained boys and men?
See comment in PubMed Commons below Appl Physiol Nutr Metab 35: 471-479.

3. Carmeli E, Coleman R, Reznick AZ (2002) The biochemistry of aging muscle. See comment in PubMed Commons below Exp Gerontol 37: 477-489.

4. Panfoli I, Ravera S, Bruschi M, Candiano G, Morelli A (2011) Proteomics unravels the exportability of mitochondrial respiratory chains. See comment in PubMed Commons below Expert Rev Proteomics 8: 231-239.

5. Judge S, Jang YM, Smith A, Hagen T, Leeuwenburgh C (2005) Ageassociated increases in oxidative stress and antioxidant enzyme activities in cardiac interfibrillar mitochondria: implications for the mitochondrial theory of aging. FASEB J 19: 419-421.

6. Santanasto AJ, Glynn NW, Jubrias SA (2015) Skeletal muscle mitochondrial function and fatigability in older adults. J Gerontol A Biol Sci Med Sci 70: 1379-1385.

7. Cadenas E, Davies KJ (2000) Mitochondrial free radical generation, oxidative stress, and aging. See comment in PubMed Commons below Free Radic Biol Med 29: 222-230.

8. Ji LL (2015) Redox signaling in skeletal muscle: role of aging and exercise. Adv Physiol Educ 39: 352-359.

9. Gomez-Cabrera MC, Sanchis-Gomar F, Garcia-Valles R, Pareja-Galeano H, Gambini J, et al. (2012) Mitochondria as sources and targets of damage in cellular aging. See comment in PubMed Commons below Clin Chem Lab Med 50: 1287-1295.

10. Sato A, Nakada K, Hayashi J (2006) Mitochondrial dynamics and aging: Mitochondrial interaction preventing individuals from expression of respiratory deficiency caused by mutant mtDNA. Biochim Biophys Acta 1763: 473-481.

11. Wei YH, Wu SB, Ma YS, Lee HC (2009) Respiratory function decline and DNA mutation in mitochondria, oxidative stress and altered gene expression during aging. Chang Gung Med J 32: 113-132.

12. Meissner C (2007) Mutations of mitochondrial DNA - cause or consequence of the ageing process? See comment in PubMed Commons below Z Gerontol Geriatr 40: 325-333.

13. Müller-Höcker J (1990) Cytochrome c oxidase deficient fibres in the limb muscle and diaphragm of man without muscular disease: an age-related alteration. J Neurol Sci 100: 14-21.

14. Ost M, Keipert S, van Schothorst EM, Donner V, van der Stelt I, et al. (2015) Muscle mitohormesis promotes cellular survival via serine/glycine pathway flux. FASEB J. 29: 1314-1328.

15. Short KR, Vittone JL, Bigelow ML, Proctor DN, Nair KS (2004) Age and aerobic exercise training effects on whole body and muscle protein metabolism. Am J Physiol Endocrinol Metab 286: E92-101.

16. Viña J, Gomez-Cabrera MC, Borras C, Froio T, Sanchis-Gomar F, et al. (2009) Mitochondrial biogenesis in exercise and in ageing. Adv Drug Deliv Rev 61:1369-1374.

17. Coen PM, Jubrias SA, Distefano G, Amati F, Mackey DC, et al. (2013) Skeletal muscle mitochondrial energetics are associated with maximal aerobic capacity and walking speed in older adults. J Gerontol A Biol Sci Med Sci 68: 447-455.

18. Boisseau N, Delamarche P (2000) Metabolic and hormonal responses to exercise in children and adolescents. See comment in PubMed Commons below Sports Med 30: 405-422.

19. Bouchard C, Rankinen T, Timmons JA (2011) Genomics and genetics in the biology of adaptation to exercise. See comment in PubMed Commons below Compr Physiol 1: 1603-1648.

20. Shefer G, Carmeli E, Rauner G, Yablonka-Reuveni Z, Benayahu D (2008) Exercise running and tetracycline as means to enhance skeletal muscle stem cell performance after external fixation. J Cell Physiol 215: 265-275. 